\title{
Synergistic Action of GA-Binding Protein and Glucocorticoid Receptor in Transcription from the Mouse Mammary Tumor Virus Promoter
}

\author{
KOLDO AURREKOETXEA-HERNÁNDEZ AND ELENA BUETTI* \\ Institute of Microbiology, University of Lausanne, CH-1011 Lausanne, Switzerland
}

Received 15 July 1999/Accepted 25 February 2000

\begin{abstract}
B lymphocytes are among the first cells to be infected by mouse mammary tumor virus (MMTV), and they play a crucial role in its life cycle. To study transcriptional regulation of MMTV in B cells, we have analyzed two areas of the long terminal repeat (LTR) next to the glucocorticoid receptor binding site, fp1 (at position -139 to -146 from the cap site) and fp2 (at -157 to -164$)$. Both showed B-cell-specific protection in DNase I in vitro footprinting assays and contain binding sites for Ets transcription factors, a large family of proteins involved in cell proliferation and differentiation and oncogenic transformation. In gel retardation assays, fp1 and $\mathrm{fp} 2$ bound the heterodimeric Ets factor GA-binding protein (GABP) present in B-cell nuclear extracts, which was identified by various criteria: formation of dimers and tetramers, sensitivity to pro-oxidant conditions, inhibition of binding by specific antisera, and comigration of complexes with those formed by recombinant GABP. Mutations which prevented complex formation in vitro abolished glucocorticoid-stimulated transcription from an MMTV LTR linked to a reporter gene in transiently transfected B-cell lines, whereas they did not affect the basal level. Exogenously expressed GABP resulted in an increased level of hormone response of the LTR reporter plasmid and produced a synergistic effect with the coexpressed glucocorticoid receptor, indicating cooperation between the two. This is the first example of GABP cooperation with a steroid receptor, providing the opportunity for studying the integration of their intracellular signaling pathways.
\end{abstract}

Mouse mammary tumor virus (MMTV) is a type B retrovirus which causes carcinomas of the mammary gland in females of susceptible mouse strains $(8,13)$. The carcinogenic transformation results from transcriptional activation of a particular class of cellular oncogenes (int genes; reviewed in reference 59). The mammary gland specificity of the oncogenic property of MMTV depends on the high viral replication rate and consequent high reinfection rate in the mammary epithelial cells, which are stimulated by pregnancy-related hormones. This hormonal stimulation has made the MMTV promoter the beststudied model for investigating the regulation of gene expression by steroid hormones (for a review, see references 7 and 51). Glucocorticoids, progesterone, and androgens (but not estrogens) strongly stimulate the rate of MMTV transcription through the binding of hormone-receptor complexes in the hormone regulatory element (HRE) (see Fig. 1) region of the proviral DNA, located upstream of the promoter in the long terminal repeat (LTR). Binding sites for additional transcription factors have been characterized, in particular for CTF (also called nuclear factor 1 [NF-1]) and Oct-1 in the HRE, and for mammary gland-specific factors further upstream in the LTR (reviewed in reference 31).

During primary infection, MMTV is transmitted in the milk from the mother to the newborn and is taken up in the intestine, where it infects local lymphocytes (reviewed in reference 43). Infected B cells express a 3'-LTR-encoded superantigen (Sag) on their surfaces that interacts with the $\mathrm{V} \beta$ domain of the T-cell receptor on specific T-cell subsets (reviewed in reference $1)$. This immune reaction results in a preferential clonal expansion of infected B cells, thus facilitating the persistence of

* Corresponding author. Mailing address: Institute of Microbiology, University of Lausanne, rue du Bugnon 44, CH-1011 Lausanne, Switzerland. Phone: 41-21-314 4100. Fax: 41-21-314 4095. E-mail: Elena .Buetti@chuv.hospvd.ch. the virus in the organism until the target mammary tissue develops. The biology of the latency phase of the viral life cycle is still largely unknown. Lymphocytes are required for virus transportation to the mammary gland, where the hormonal stimulation is the most important factor for virus production and tumorigenicity. However, lower levels of virus expression are also detected in a specific set of organs, in particular in lymphoid tissues. Tight control of viral gene expression is suggested by the observations that (i) the pattern of expressing organs in mice transgenic for a reporter gene linked to the MMTV LTR is the same as that in an infected mouse and (ii) the presence of hormone receptors is not sufficient to allow LTR activation in a nonpermissive organ (reference 52 and references therein). Since B lymphocytes are essential for virus propagation in the infected animal (33), we are interested in the regulation of viral expression in these cells. As this implies the activation of the standard proviral promoter in the LTR for the synthesis of genomic and spliced RNAs, we investigated the sequence requirements and interacting transcription factors in B-lymphoma cell lines used as a model.

Both B and T cells have been shown to be infected in the mouse and in cell culture and to be able to transmit virus to other cells (21). Earlier studies were focused on pathological situations, in particular on T-cell lymphomas characterized by an amplification of integrated proviruses carrying large deletions and rearrangements in their LTRs (reference 62 and references therein). Lymphocytes of the B lineage, B-cell lines, and B lymphomas express endogenous MMTV sequences at detectable levels, without amplification or rearrangement of the proviral DNA (reviewed in reference 16). In this study, we analyzed the activity of the main LTR promoter in mature B-cell lines. We uncovered two sequences which are required for glucocorticoid stimulation in B cells and showed that they bind proteins of the Ets family of transcription factors, namely, the heterodimeric GA-binding protein (GABP) $(10,37,38)$. 
The DNA-binding component is the $\alpha$ subunit (GABP $\alpha$ ) containing the conserved Ets domain, a winged helix-turn-helix protein motif (6). The $\beta$ subunit (GABP $\beta$ ) is bound to $\mathrm{GABP} \alpha$ via repeats of the Notch-ankyrin type (19). On two neighboring sites in the DNA, tetramers are formed by interaction between the $\beta$ subunits, and all these protein-protein interactions greatly stabilize the binding to DNA (reviewed in reference 28). Both DNA binding and heterodimerization are regulated by the reduction-oxidation state of specific cysteine residues $(15,45)$. We also demonstrated, using transient-transfection assays in B-cell lines with LTR constructs carrying specific mutations, that both Ets sites are important for glucocorticoid stimulation, whereas they were not involved in the basal level of transcription. Exogenously expressed GABP increased the hormone-induced level of transcription, as did exogenously expressed glucocorticoid receptor, and both required the integrity of the Ets sites. Coexpressed receptor and GABP resulted in a synergistic potentiation, suggesting a functional cooperation between GABP and the glucocorticoid receptor in MMTV transcription in B cells.

\section{MATERIALS AND METHODS}

Cell lines. The M12.4 mouse B-lymphoma cell line (M12) was cultured in Dulbecco modified eagle's medium (DMEM) containing 5\% heat-inactivated fetal calf serum (FCS), $50 \mu \mathrm{M}$ 2-mercaptoethanol, $2 \mathrm{mM}$ L-glutamine, and antibiotics. The A20 mouse B-lymphoma cell line was grown in RPMI 1640 medium, $10 \%$ FCS, antibiotics, and $50 \mu \mathrm{M}$ 2-mercaptoethanol. Both were from R. Lees, Ludwig Institute for Cancer Research, Epalinges, Switzerland. Ltk aprt $^{-}$cells (mouse fibroblasts) were maintained in DMEM, 10\% FCS, and antibiotics. Cultures were kept at $37^{\circ} \mathrm{C}$ in a humidified $5 \% \mathrm{CO}_{2}$ atmosphere.

Reagents and expression plasmids. The expression plasmids sRSV-GABP $\alpha$ and sRSV-GABP $\beta 1$, bacterially expressed recombinant GABP $\alpha$ and GABP $\beta 1$, and rabbit polyclonal antibodies against these proteins (23) were kind gifts of E. Flory. Immunoglobulin Gs (IgGs) were purified with HiTrap protein G affinity columns (Pharmacia). pCMV-thioredoxin was a gift of I. Kerblat, the human glucocorticoid receptor expression plasmid pRSV-hGR $\alpha$ (26) was a gift of R. Evans, and the mouse glucocorticoid receptor expression plasmid pSG5mGR (derived from pSV2GRWrec [18]) was a gift of M. G. Parker.

Plasmid construction. The wild-type MMTV LTR (GR strain; from the PstI site at position 11 in the LTR to the PvuII site at its $3^{\prime}$ end: pLSwt [36]) and the mutants LS $-175 /-166$ and $\Delta-193 /-162$ (carrying an octameric HindIII linker inserted between the indicated positions from the RNA start site [12]) were subcloned as SalI (filled-in)-BamHI fragments into the firefly luciferase pGL3Basic vector (Promega) at the SmaI and BglII sites. The pGL3 constructs with LTRs truncated at position -303 were made in the same vector by inserting the fragment from -303 (filled-in StyI site) to the artificial Bam HI site next to the $3^{\prime}$ end of the LTR. The negative-control plasmid $\Delta \mathrm{P}$ (lacking the standard basal promoter) was made from pGL3/LTRwt by isolating the fragment from the SacI site in the polylinker upstream of the LTR to the internal SacI site at position -105 and recloning it into a SacI-cut pGL3-Basic vector. Mutagenesis of the fp1 and $\mathrm{fp} 2$ sites was performed by the method of splicing by overlap extension (34). Briefly, two internal primers of 56 nucleotides containing the two mutated areas (in boldface below) corresponding to the observed footprints $\mathrm{fp} 1$ and $\mathrm{fp} 2$ and an internal SpeI restriction site (underlined) created by a single-nucleotide mutation at position -151 (boldface and underlined) were synthesized: left ( -174 to -119) 5' TTCTTAAACACCTTCGTGGAGACTAGTGTGGGAAATAGTTGG TTTGGTATCAAATG $3^{\prime}$ and right $(-131$ to -186$) 5^{\prime}$ AACCAACTATTTCC CACACTAGTCTCCACGAAGGTGTTTAAGAACAGTTTGTAACC 3'. We also used two external primers: left, (-668) 5' GAGAGCAGTACAAGGAC TAA 3', and right, (+131) 5' CGCAGTCGGCCGACCTGAGGG 3'. Two PCRs were carried out first: one with the internal primer right and the external left, and the second with the internal primer left and the external right. After gel purification, the products were combined in a third PCR using only the external primers. The final product was digested with StuI and BstEII and recloned in pGL3/LTRwt to replace the corresponding wild-type fragment. A control LTR construct with only the SpeI site was generated by mutating the A at -151 to a $\mathrm{T}$, using the technique described above but with internal oligonucleotides spanning positions -159 to -140 and containing the mutation. The presence of the mutations was verified by sequencing. Recombination of LTR (fp1-fp2) with LTR (wild type-SpeI) to obtain singly mutated LTRs was performed using the SpeI site and the StuI or BstEII site.

Transfections. Cell cultures were split the day before transfection to obtain cultures in the late phase of exponential growth. The amount of reporter plasmid was chosen to be in the linear range of expression, determined in preliminary titration experiments. M12, A20, and $\mathrm{Ltk}^{-}$cells were transfected by the DEAEdextran method following different protocols. For M12 cells, after being washed with a buffer containing $20 \mathrm{mM}$ HEPES (pH 7.2), $137 \mathrm{mM} \mathrm{NaCl}, 0.5 \mathrm{mM} \mathrm{KCl}$, and $3 \mathrm{mM}$ glucose, $5 \times 10^{6}$ cells were incubated at $37^{\circ} \mathrm{C}$ for $1 \mathrm{~h}$ with $0.5 \mathrm{ml}$ of DMEM (without serum) containing DEAE-dextran $(200 \mu \mathrm{g} / \mathrm{ml}$; Amersham Pharmacia), $0.75 \mathrm{pmol}$ (equal to $3 \mu \mathrm{g}$ for wild-type LTR) of the LTR-pGL3 constructs, and $50 \mathrm{ng}$ of the Renilla luciferase expression vector pRL-SV40 or pRL-TK (Promega) and were cultured in complete medium thereafter. The cells were harvested $24 \mathrm{~h}$ after transfection. Transfection experiments with A20 cells were carried out following a different DEAE-dextran protocol (29). Briefly, $10^{7}$ cells in $1.5 \mathrm{ml}$ of Tris-saline buffer-DEAE-dextran $(500 \mu \mathrm{g} / \mathrm{ml}), 0.75 \mathrm{pmol}$ of LTR constructs, and $50 \mathrm{ng}$ of pRL-SV40 were incubated for $20 \mathrm{~min}$ at room temperature followed by the addition of $10 \mathrm{ml}$ of RPMI- $0.1 \mathrm{mM}$ chloroquine and further incubation for $1 \mathrm{~h}$ at $37^{\circ} \mathrm{C}$. Finally, the cells were cultured in complete medium and harvested $48 \mathrm{~h}$ later. Ltk $^{-}$cells were transfected by the protocol described previously (11) with 0.75 pmol of LTR constructs and $50 \mathrm{ng}$ of pRL-SV40. When required, the synthetic steroid hormone dexamethasone was added in all three cell lines 3 to $5 \mathrm{~h}$ before harvesting. Luciferase assays were performed with the Dual luciferase assay kit (Promega), and measurements were done in a Berthold Lumat luminometer. The results were expressed as the ratio of firefly luciferase activity to Renilla luciferase activity or, in some cases, when cotransfected transcription factors affected the level of Renilla luciferase, as firefly luciferase activity per constant amount of protein (determined by the bicinchoninic acid assay [Pierce]). The reproducibility of the transfection conditions was verified beforehand. In experimental series, the standard deviation between independently transfected samples was $<5 \%$.

Nuclear extracts. Extracts were made from logarithmically growing A20 or M12 B cells (20) with modifications (9). The cells were homogenized in hypotonic buffer, and the nuclei were recovered by centrifugation at $30,000 \times g$ for $30 \mathrm{~s}$. The nuclei were extracted in buffer C ( $20 \mathrm{mM}$ HEPES [pH 7.9], $0.2 \mathrm{mM}$ EDTA, $0.2 \mathrm{mM}$ EGTA, $2 \mathrm{mM}$ dithiothreitol [DTT], $20 \%$ glycerol, $0.15 \mathrm{mM}$ spermine, $0.75 \mathrm{mM}$ spermidine, $1 \mathrm{mM}$ phenylmethylsulfonyl fluoride, $0.4 \mathrm{M}$ $\mathrm{NaCl}$, and a cocktail of protease inhibitors [Complete and Mini; Roche Molecular Biochemicals]). The extracts were recovered by centrifugation at 300,000 $\times$ $g$ for $45 \mathrm{~min}$ and precipitated with ammonium sulfate $\left[0.3 \mathrm{~g}\right.$ of solid $\left(\mathrm{NH}_{4}\right)_{2} \mathrm{SO}_{4}$ per $\mathrm{ml}$ of supernatant]. Resuspension, dialysis, and determination of protein concentration by optical density were performed by the method of Gorski et al. (27). For the preparation of extracts of A20 cells treated with the oxidant diethyl maleate (DEM [45]), $1 \mathrm{mM}$ DEM (Sigma) was added to the culture medium $2 \mathrm{~h}$ before harvesting. Nuclear extracts of $\mathrm{Ltk}^{-}$cells were prepared as described previously (11).

DNase I footprinting. DNase I footprinting assays were performed by the following modifications $(41,47)$ of the original method (24). An asymmetrically radiolabeled DNA probe was prepared from a plasmid with a truncation at position -303 of pLSwt (12), obtained by religating an EcoRI-StyI-cut pLSwt after filling in with Klenow polymerase. The resulting pLSwt $(-303)$ plasmid was digested at the (reconstituted) EcoRI site, end labeled with $\left[\gamma^{32} \mathrm{P}\right] \mathrm{ATP}$ and polynucleotide kinase, and digested with Bam HI. The $0.45-\mathrm{kb}$ fragment was purified from agarose gels, and an aliquot was used for the purine sequencing reaction (46). The labeled fragment $(10 \mathrm{fmol}), 1 \mu \mathrm{g}$ of double-stranded poly[d(IC)] competitor, and nuclear extracts in a $20-\mu l$ binding reaction were incubated on ice for $30 \mathrm{~min}$ (11) and digested with DNase I (Roche Molecular Biochemicals) for $5 \mathrm{~min}$ at $0^{\circ} \mathrm{C}$. Samples without nuclear extracts received a 20-fold dilution of DNase I for 2 or 5 min. After proteinase K digestion, extraction, and precipitation (11), the DNA was separated by electrophoresis on $6 \%$ denaturing polyacrylamide gels (46), fixed, and dried prior to autoradiography at $-80^{\circ} \mathrm{C}$ with intensifying screens.

Gel mobility shift assay. Double-stranded probes were made by annealing a 5 '-end-labeled oligonucleotide with its unlabeled complementary strand. Their sequences were as follows: for fp1 $(-154$ to -133$), 5^{\prime}$ GACAAGTGGTTTCC TGAGTTGG $3^{\prime}$ and $5^{\prime}$ CCAACTCAGGAAACCACTTGTC $3^{\prime}$; for fp2 (-175 to -152$), 5^{\prime}$ ggaCTTAAAACAAGGATGTGAGAC $3^{\prime}$ and 5' GTCTCACATC CTTGTTTTAAGtcc $3^{\prime}$ (the nucleotides in lowercase letters were added to avoid an overlap with the glucocorticoid response element [GRE]); for fp1m (mutated nucleotides are in boldface), 5' GACAAGTGGTGGAAATAGTTGG 3' and 5' CCAACTATTTCCACCACTTGTC 3'; for fp2m, 5' ggaCTTAAAACACTTCG TGGAGAC 3' and 5' GTCTCCACGAAGTGTTTTAAGtcc 3'; for fp1-fp2 (equivalent to D, a double oligonucleotide containing both binding sites; -172/ -133), 5' CCAACTCAGGAAACCACTTGTCTCACATCCTTGTTTTAAG 3' and 5' CTTAAAACAAGGATGTGAGACAAGTGGTTTCCTGAGTTGG 3'; and for VW (promoter of adenovirus 2; position -2/-41 [54]), 5' GAAGGGG GGCTATAAAAGGGGGTGGGGGCGCGTTCGTCC $3^{\prime}$ and 5' GGACGAA CGCGCCCCCACCCCCTTTTATAGCCCCCCTTC $3^{\prime}$. Mobility shift assays were carried out as described previously (17). In brief, $20-\mu l$ binding reaction mixtures in 125 mM HEPES (pH 7.5), 50 mM EDTA, 5 mM DTT, 10\% glycerol, $0.5 \%$ Nonidet P-40, $1 \mathrm{mM}$ phenylmethylsulfonyl fluoride and $12.5 \mu \mathrm{g}$ of bovine serum albumin $/ \mathrm{ml}$ were preincubated with $4 \mu \mathrm{g}$ of nuclear extracts and $1 \mu \mathrm{g}$ of double-stranded poly[d(I-C)] for $10 \mathrm{~min}$ at $20^{\circ} \mathrm{C}$ (the same pattern was observed at $\left.0^{\circ} \mathrm{C}\right)$. Labeled probe $(10 \mathrm{fmol})$ was added, and the reaction was continued for another $20 \mathrm{~min}$. After the addition of Ficoll 400 to a final concentration of $5 \%$, the reaction mixtures were loaded onto $5 \%$ polyacrylamide gels containing $0.5 \times$ Tris-borate-EDTA. The gels were electrophoresed in $0.5 \times$ Tris-borate-EDTA buffer at $4^{\circ} \mathrm{C}$ for $2 \mathrm{~h}$ at $200 \mathrm{~V}$. They were transferred to Whatman $3 \mathrm{MM}$ paper, dried, and autoradiographed. In competition experiments, a 300-fold excess of 
unlabeled, double-stranded oligonucleotides was incubated with the nuclear extracts $5 \mathrm{~min}$ before the probe was added. For the experiments with antibodies, 2 $\mu \mathrm{g}$ of purified IgGs was added to the preincubation mixture on ice for $20 \mathrm{~min}$ prior to addition of the probe, and the reaction was prolonged for $30 \mathrm{~min}$ at $20^{\circ} \mathrm{C}$.

\section{RESULTS}

Identification of binding sites for B-cell nuclear proteins in the HRE of the MMTV LTR. We demonstrated in a previous study that tissue-specific factors bind to a DNA sequence immediately $5^{\prime}$ to the distal glucocorticoid receptor binding site (14). We also observed a correlation between the pattern of protection and the permissivity for MMTV expression of the mouse organ from which the nuclear extracts were made, e.g., spleen (permissive) versus liver (nonpermissive). To look for cell-type-specific factors, we further analyzed the DNA-protein interactions occurring in the HRE that are able to modify the promoter activity. We compared DNase I footprinting patterns of nuclear extracts from the fibroblastic $\mathrm{Ltk}^{-}$cell line with those of a mouse B-lymphoma cell line, M12, which could also be used for functional studies by transient-expression assays. $\mathrm{Ltk}^{-}$cells have been utilized for numerous transcription studies, as they are permissive for MMTV expression and display high stimulation factors by glucocorticoid hormones $(36,58)$. Neither cell type was treated with glucocorticoid hormones before the preparation of the extracts. However, as observed previously (47), crude nuclear extracts from cells with a high receptor level yield a footprint in the distal GRE even in the absence of treatment with the hormone, due to residual cytoplasmic receptor activated by the ammonium sulfate precipitation. Figure 1 (lanes 5 to 7 ) shows that M12 cells, which represent a mature B-cell stage, lack a distinct footprint in the promoter-distal region $(-175$ to -200$)$ that is present in $\mathrm{Ltk}^{-}$ cells (lane 4) and includes the GRE and the upstream tissuespecific binding site DRa, also seen previously with total spleen nuclear extracts (14). This indicates that M12 cells most likely contain a relatively low level of glucocorticoid receptor compared to L cells. In the basal promoter region ( -40 to -80$)$, a protection is visible with the M12 extract mainly in the CTF/ NF-I binding site $(-60$ to -80$)$ and also, at high concentrations of extract, in the octamer motif region $(-40$ to -60$)$. The cap site region $(+1)$ is protected by L-cell extracts but not by M12-cell extracts. In contrast, two narrow areas on the $3^{\prime}$ side of the GRE were specifically protected by M12 nuclear extracts, one around $-140(-139$ to -146 ; called fp1) and the other around -160 ( -157 to -164 ; called fp2).

To assess whether the observed footprints were indeed caused by proteins bound to $\mathrm{fp} 1$ and $\mathrm{fp} 2$, an electrophoretic mobility shift assay was carried out with M12 nuclear extracts and radiolabeled double-stranded oligonucleotides containing either fp1 or fp2 (Fig. 2B). Complexes with low mobility were observed with each probe. The specificity of each complex was verified by competition, which was apparent using the homologous unlabeled oligonucleotide (Fig. 2A, lanes 4 and 11) but not using the unrelated oligonucleotide VW from the adenovirus promoter (Fig. 2A, lanes 1 and 7). The fp1 and $\mathrm{fp} 2$ complexes had similarly low electrophoretic mobilities (complex I). Cross competition between fp1 and fp2 (Fig. 2A, lanes 5 and 10) indicated that similar binding activities interacted with these probes. Oligonucleotides containing mutations in the bases involved in the footprints (Fig. 2B) did not form the specific complexes when used as probes (Fig. 2A, lanes 14 and 16) and did not compete with the wild-type probes (Fig. 2A, lanes 2 and 3 and lanes 8 and 9), confirming the specificity of complex I.

Transcriptional activity of LTRs with mutations in the fp1 and fp2 sites. The same mutations of fp1 and fp2 which elim-

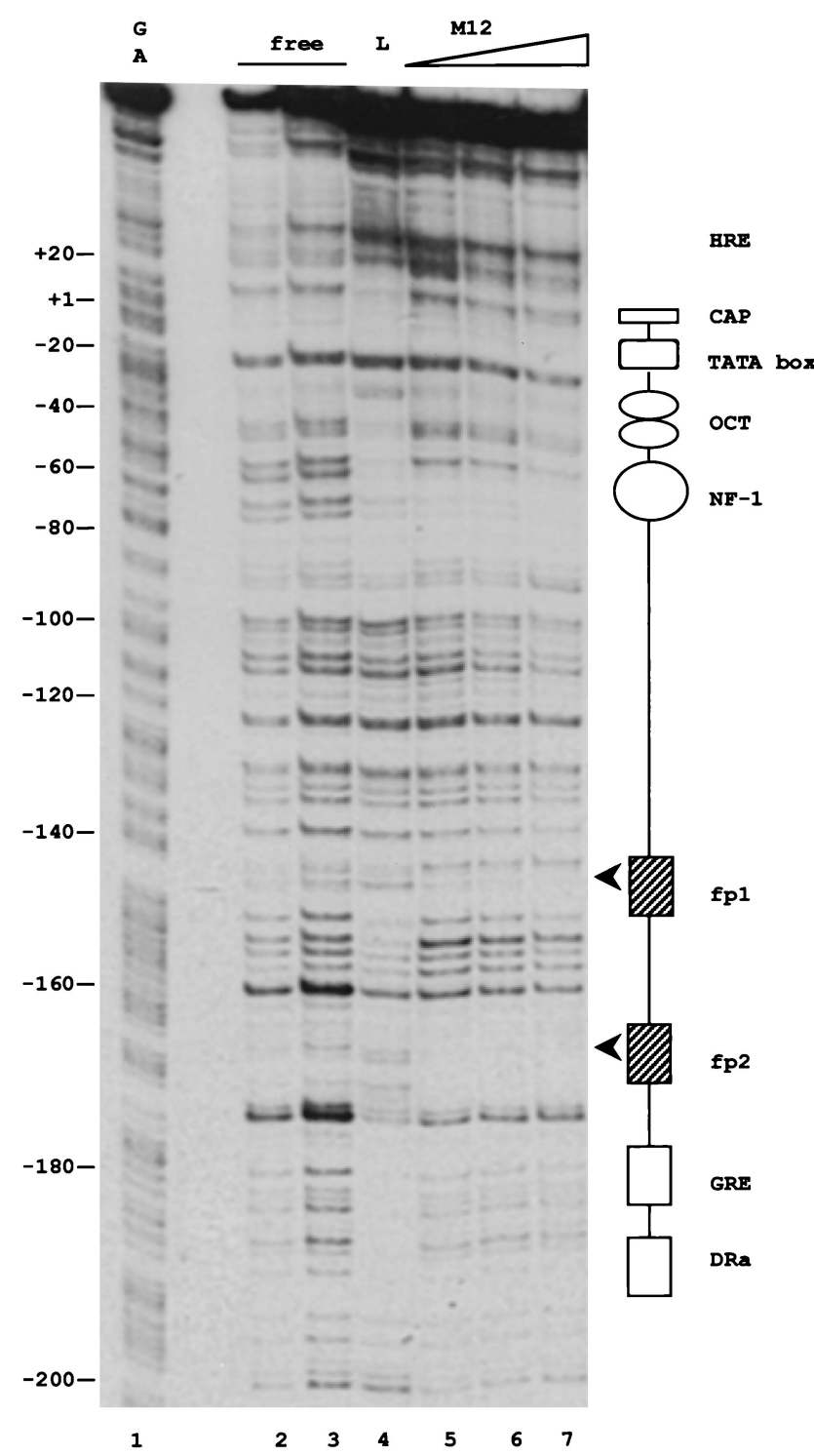

FIG. 1. B-cell factors binding in vitro to the HRE of MMTV. DNase I footprinting analysis with nuclear extracts of the M12 B-cell line shows two protected sites, fp1 and fp2 (arrowheads), not seen with nuclear extracts of the fibroblastic $\mathrm{Ltk}^{-}$cell line. A DNA fragment comprising the sequences from the Sty I restriction site at positions -303 to +133 , where a synthetic BamHI linker was inserted, was $5^{\prime}$ end labeled at the StyI site. The fragment was incubated without added proteins (lanes 2 and 3), with $60 \mu \mathrm{g}$ of nuclear proteins from L cells (lane 4), or with 48 (lane 5), 72 (lane 6), or 104 (lane 7) $\mu \mathrm{g}$ of nuclear proteins from M12 cells. The complexes were subjected to DNase I digestion and separated on a sequencing gel. Lane 1 contains a purine sequencing reaction of the probe, and the numbers on the left indicate the number of nucleotides from the transcription start site $(+1)$. Also represented in the scheme on the right are known factor-binding sites in the HRE of the MMTV LTR that are protected by L-cell extracts: RNA initiation site (CAP), TATA box, binding sites for octamer factors (OCT), for CTF/NF-1, for the glucocorticoid receptor (the distal GRE), and for a tissue-specific factor (DRa [14, 47]).

inated the formation of complexes in vitro were engineered into LTRs (either complete or $5^{\prime}$ truncated at -303 to eliminate the effects of upstream sequences) that directed the synthesis of the firefly luciferase reporter gene. The transcriptional activities of the various plasmids were assayed in transient-transfection experiments with M12 cells and also, to confirm the results, with a second B-lymphoma cell line, A20. 
A
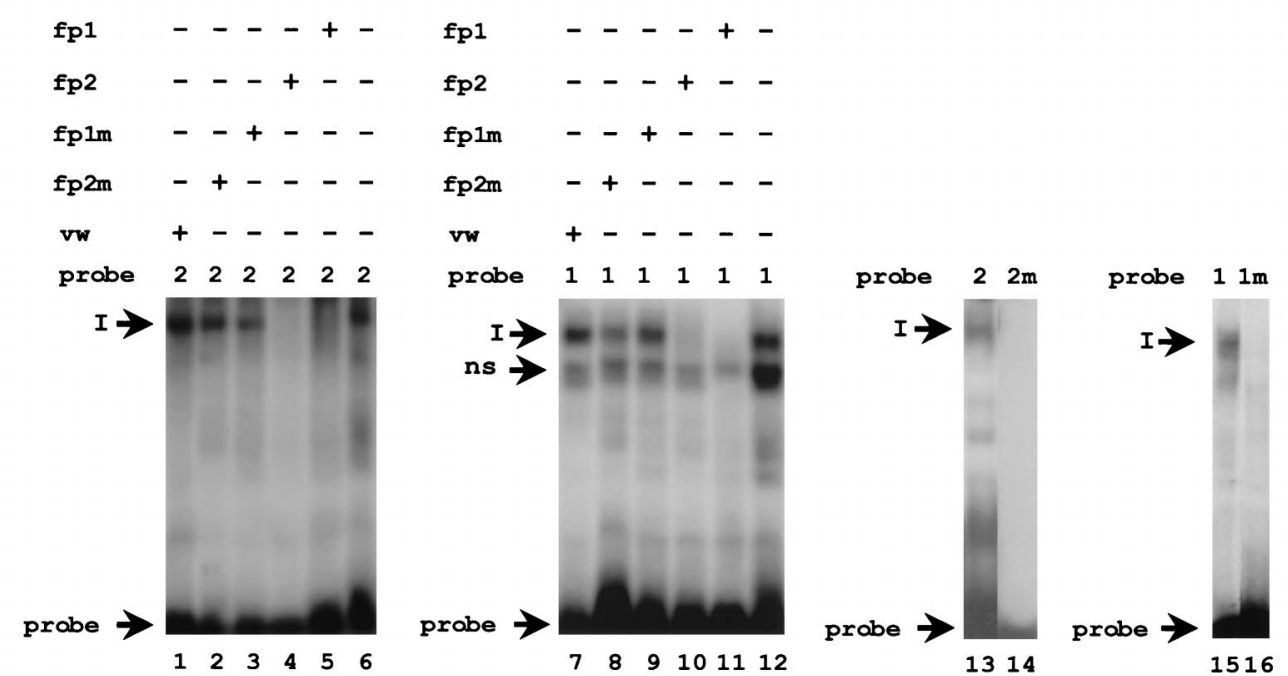

B

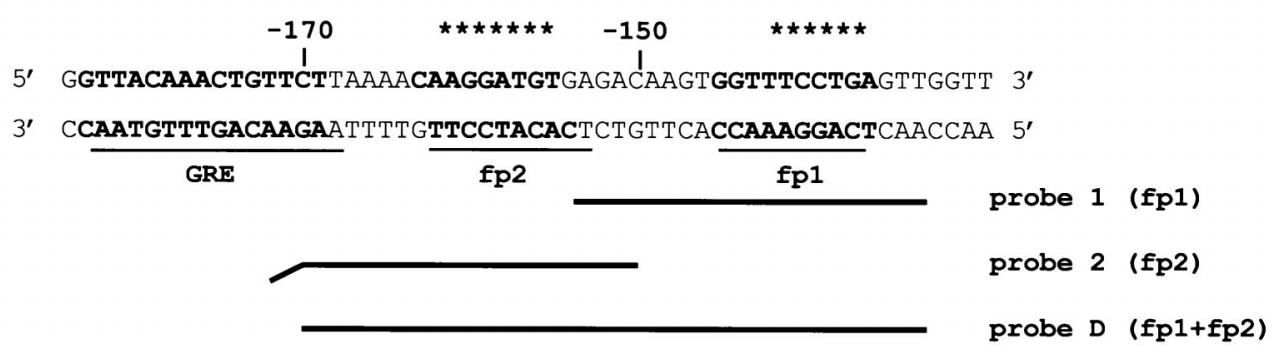

FIG. 2. B-cell nuclear extracts form similar complexes on probes with the $\mathrm{fp} 1 \mathrm{or} \mathrm{fp} 2$ sequences. Gel retardation assays (A) with M12 nuclear extracts and end-labeled oligonucleotide probes (B) are shown. Mutated oligonucleotides $(1 \mathrm{~m}$ and $2 \mathrm{~m})$ contained transversions at the positions denoted by asterisks in the sequence in panel $\mathrm{B}$, where the GRE and the B-cell footprints fp1 and fp2 are underlined and in bold. (A) Protein-DNA complexes were resolved on nondenaturing polyacrylamide gels, followed by autoradiography. Where indicated (+; above the probes), a 300-fold excess of competitor DNA, either homologous, heterologous, mutated (m), or nonspecific (vw, an oligonucleotide with the sequence of the adenovirus-2 promoter), was included in the preincubation mixture. Specific complexes with similar mobilities (I) on fp1 (1) or fp2 (2) showed cross competition (lanes 4, 5, 10, and 11). Mutations in the fp1 (1m) or fp2 (2m) sites abolished the formation of complex I (lanes 14 and 16), which was not affected by adding fp1m (lanes 3 and 9) or fp2m (lanes 2 and 8 ) in the competition experiment. ns, nonspecific complex.

The measured firefly luciferase activity was standardized with respect to the activity of a cotransfected plasmid carrying the Renilla luciferase gene driven by either the simian virus 40 (SV40) promoter or the thymidine kinase promoter of herpes simplex virus. The cells were either left untreated (to determine the basal level of promoter activity) or stimulated for 3 to $5 \mathrm{~h}$ by the addition of the synthetic glucocorticoid hormone dexamethasone (at a concentration of $50 \mathrm{nM}$ ). Luciferase activity was measured in cell extracts prepared 24 (M12 cells) or 48 (A20 cells) h after transfection. None of the mutated constructs differed significantly from their wild-type counterparts in basal promoter activity (Fig. 3A and B, - dex samples). In contrast, mutation of both $\mathrm{fp} 1$ and $\mathrm{fp} 2$ abolished the stimulatory effect of dexamethasone in both A20 and M12 cell lines (Fig. 3A and B, + dex samples). Plasmids carrying one mutation, either in $\mathrm{fp} 1$ or in $\mathrm{fp} 2$, had only a partial activity (Fig. 3A and $\mathrm{B}$ ), indicating that both sites contributed roughly equally to the glucocorticoid induction in B cells. The extent of stimulation by the wild-type LTR was about 10-fold in A20 cells (Fig. 3A) and about 3-fold in M12 cells (Fig. 3B). The transcriptional activity of the LTR carrying the SpeI site (A-to-T mutation at position -151) used for recombining the single fp site mutations was indistinguishable from that of the wild-type
LTR. An LTR lacking the promoter downstream of position -105 (Fig. 3, bars $\Delta \mathrm{P}$ ) was used as a negative control. The double mutation in $\mathrm{fp} 1$ and $\mathrm{fp} 2$ also abolished dexamethasone stimulation with an LTR truncated at position -303 , both in A20 cells (Fig. 3C) and in M12 cells (not shown). Such truncated plasmids had overall higher expression levels (also under unstimulated conditions [data not shown]), which were probably due to the removal of negative regulatory elements present in the LTR upstream of position -303 (42). The proximity of $\mathrm{fp} 1$ and $\mathrm{fp} 2$ to the distal GRE, together with the observed suppression of the glucocorticoid response in $\mathrm{fp} 1$ and fp2 mutants, suggested that the in vitro complex I may interact with the glucocorticoid receptor bound in the adjacent GRE (positions -171 to -182 ). While this sequence element is essential for the glucocorticoid response in L cells (12), its function had to be tested in B cells. We therefore performed transient-expression assays in A20 cells with luciferase reporter plasmids under the control of an LTR with the distal GRE deleted (with a HindIII linker replacing the sequence between -193 and -162) or an LTR carrying an 8-base substitution in the GRE (mutant LS -175/-166). Both plasmids show a 10to 20-fold reduction in glucocorticoid response in L cells (12). As shown in Fig. 3D, both mutants were drastically impaired in 
A

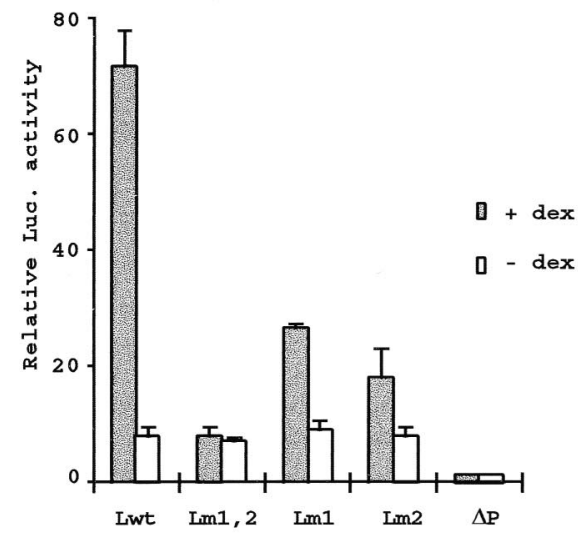

C

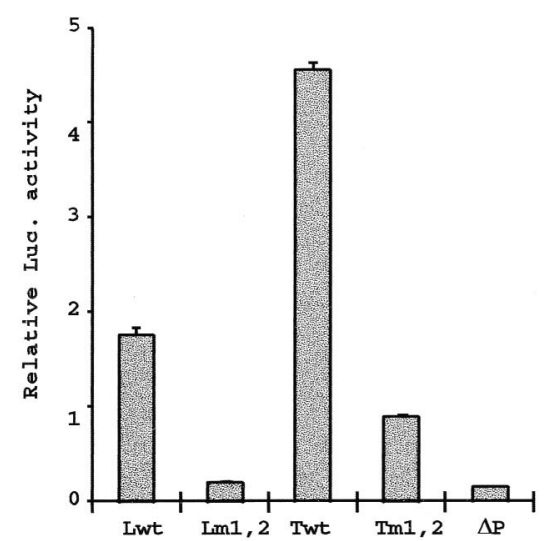

B

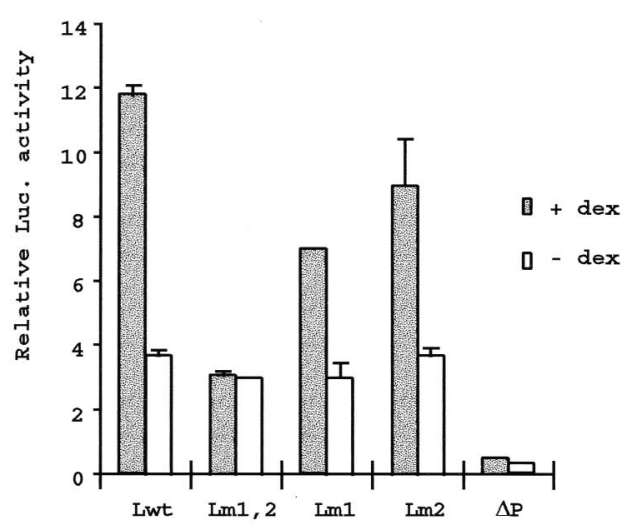

D

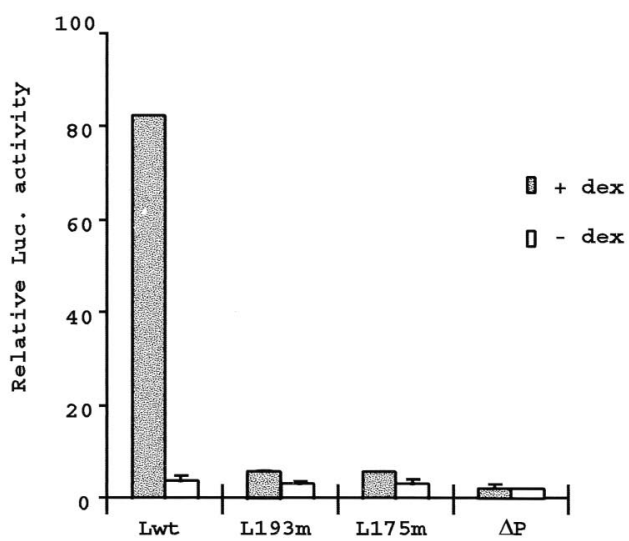

FIG. 3. Factors binding in $\mathrm{fp} 1$ and $\mathrm{fp} 2$ cooperate in the transcriptional response to glucocorticoids in B cells. pGL-3 luciferase reporter plasmids were transiently transfected into A20 cells (A, C, and D) or M12 cells (B) and stimulated ( + dex) or not ( - dex) with the glucocorticoid hormone dexamethasone (50 nM) for 5 h. The relative luciferase (Luc.) activity was calculated as the ratio to the activity of the cotransfected SV40-Renilla luciferase internal standard. Individual experiments are shown, which have been repeated with the same results at least twice. The error bars show the standard deviations between duplicate samples. (A and B) Luciferase activities of plasmids containing a wild-type LTR (Lwt) or LTRs with mutations in fp1 and fp2 (Lm1,2), in fp1 (Lm1), or in fp2 (Lm2). Plasmid $\Delta \mathrm{P}$ contained an LTR lacking the sequences downstream of position -105 , including the promoter, and serves as a negative control. (C) Luciferase activity ( + dex) of plasmids containing LTRs truncated at position -303 (Twt and Tm1,2). (D) LTRs with mutations in the GRE are unresponsive to dexamethasone in A20 B cells. In the mutated LTRs an octameric HindIII linker replaces the sequences between -193 and -162 (in L193m) or between -175 and -166 (in L175m).

their responses to dexamethasone, demonstrating that the distal GRE is responsible for the glucocorticoid stimulation of the MMTV LTR in B cells as well (similar results were obtained in the M12 cell line [data not shown]). From the results shown in Fig. 3, we concluded that $\mathrm{fp} 1$ and $\mathrm{fp} 2$ are required, in addition to the GRE, for glucocorticoid-stimulated MMTV expression in these B-cell lines. We were therefore interested in identifying the factors which bind to these glucocorticoid coregulatory sites in the HRE.

Identification of fp1 and $\mathrm{fp} 2$ binding factors from B-lymphoma cell lines. The DNA sequence of the HRE was submitted to the World Wide Web Signal Scan Information Matrix Database Search Service (http://bimas.dcrt.nih.gov/molbio/matrixs/) for analysis of homologies to published recognition sequences. The result indicated that $\mathrm{fp} 1$ and $\mathrm{fp} 2$ could interact with proteins of the Ets family of transcription factors, which comprises approximately 30 known members to date. These are characterized by a common DNA-binding Ets domain of approximately 85 amino acids, and they are involved in cell proliferation and differentiation and embryonic development (reviewed in reference 60). The most likely candidates were GABP, at both fp1 and fp2, and PEA3, for which a consensus binding sequence is present in fp2. PEA3 is a single-polypeptide Ets factor first described as a regulator of the polyomavirus enhancer (61), while GABP is a heterodimeric DNA-binding complex originally isolated as a factor involved in immediate-early gene activation of herpes simplex virus type 1 $(37,38)$. A human homolog is nuclear respiratory factor 2 (NRF-2, or E4TF-1 [30, 53]). GABP is composed of two distinct subunits, GABP $\alpha$, which binds DNA via an Ets domain, and $\mathrm{GABP} \beta$, which interacts in a highly specific manner with $\mathrm{GABP} \alpha(10)$ through Notch-ankyrin repeats, thereby greatly stabilizing GABP $\alpha$ binding to DNA. To test whether GABP from $B$ cells binds to fp1 and fp2, we carried out gel retardation assays with nuclear extracts preincubated with polyclonal antiserum directed against $\mathrm{GABP} \alpha$ or GABP $\beta$. These antisera had been shown to inhibit GABP binding to its site in the distal interleukin-2 (IL-2) enhancer (3). Whereas an unrelated anti- 
A

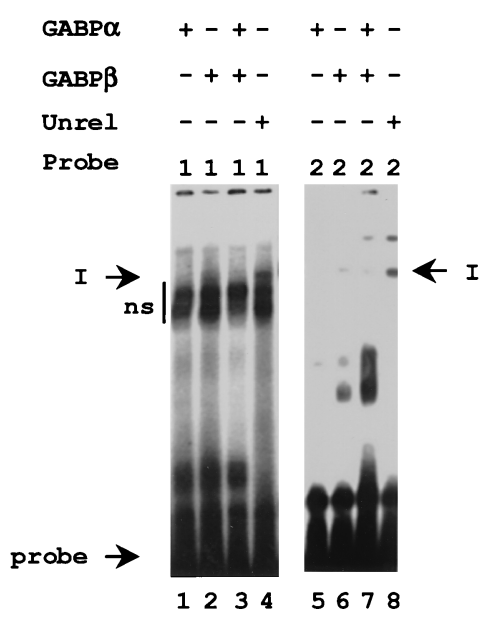

D

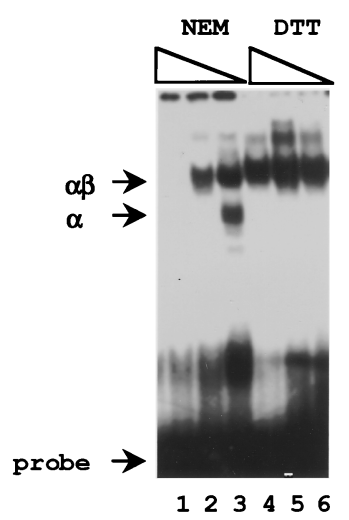

B

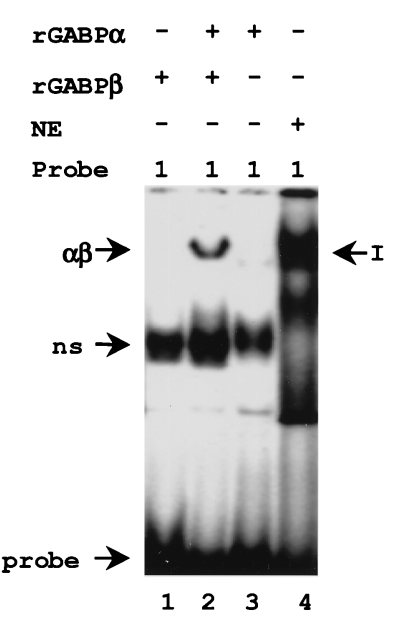

$\mathbf{E}$

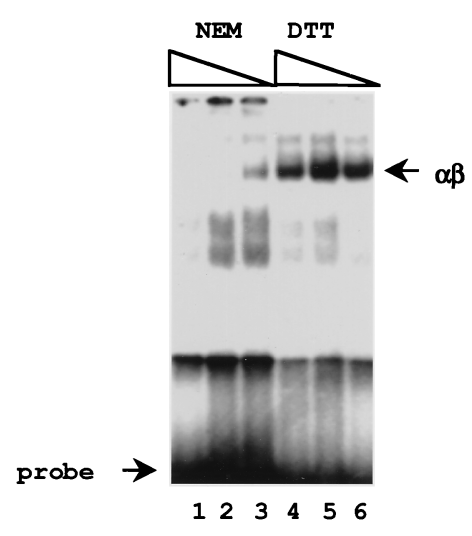

C

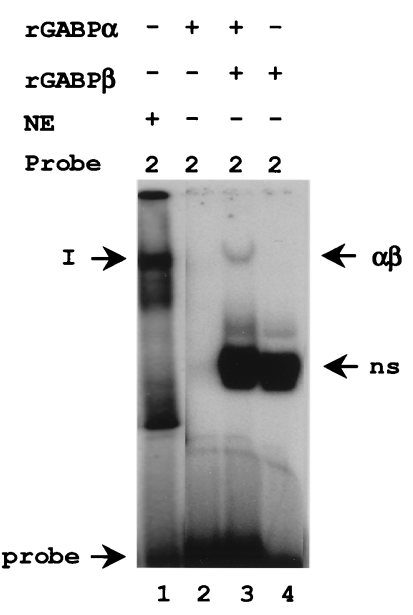

$\mathbf{F}$

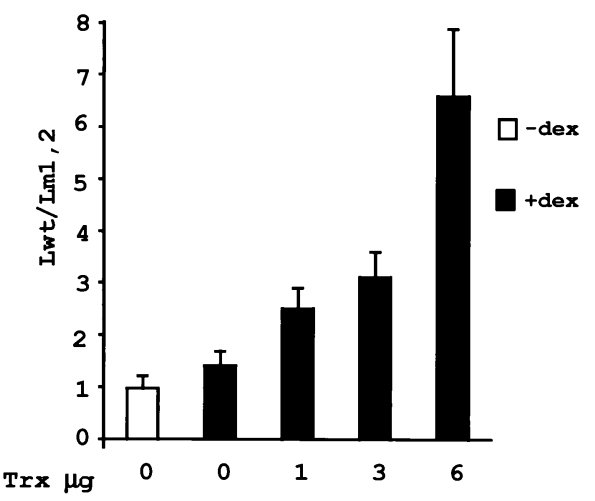

FIG. 4. GABP binds to fp1 and fp2 and is present in complex I of B-cell extracts in a redox-sensitive form. (A to E) Gel retardation assays with end-labeled oligonucleotide probes. (A) Specific antibodies against GABP $\alpha$ and/or GABP $\beta$ (lanes 1 to 3 and 5 to 7 ) abolished the formation of complex I-GABP $\alpha \beta$ (lanes 4 and 8 ) on ${ }^{32} \mathrm{P}$-labeled oligonucleotides containing either fp1 (1) or fp2 (2). A20 nuclear extracts were preincubated with the polyclonal antibodies (purified IgGs) prior to addition of the probes. A similarly purified unrelated (Unrel) antibody was used as a negative control (lanes 4 and 8 ). (B and $\mathrm{C}$ ) Recombinant GABP $\alpha$ (rGABP $\alpha$ ) and/or GABP $\beta$ was incubated with the fp1 probe (B, lanes 1 to 3 ) or the fp2 probe (C, lanes 2 to 4$)$ in parallel with $A 20$ nuclear extracts $(\mathrm{NE})$ (B, lane 4 , and $\mathrm{C}$, lane 1). ns, nonspecific complex (also present in the non-DNA-binding GABP $\beta$ sample). (D and E) Redox sensitivity of complex formation in vitro. Treatment with NEM $(0.25,0.5$, or $5 \mathrm{mM})$ or DTT $(2,3$, or $4 \mathrm{mM})$ for $20 \mathrm{~min}$ at $20^{\circ} \mathrm{C}$ was carried out in the binding reaction with A20 nuclear extracts and the fp1 (D) or the fp $2(\mathrm{E})$ probe. (F) Redox sensitivity of reporter activity in vivo. M12 cells were cotransfected with a plasmid expressing thioredoxin (Trx; $0,1,3$, or $6 \mu$ g) and a vector plasmid (to a total of $6 \mu \mathrm{g}$ ) plus $0.75 \mathrm{pmol}$ of a luciferase reporter under the control of either the wild-type LTR (Lwt) or an LTR with mutations in fp1 and fp2 (Lm1,2). The cells were cultured in the presence of $1 \mathrm{mM} \mathrm{H}_{2} \mathrm{O}_{2}$ for $24 \mathrm{~h}$, and dexamethasone $(50 \mathrm{nM})$ was added to the + dex samples during the last $4 \mathrm{~h}$ before harvesting. The firefly luciferase activity of the extracts was measured and normalized to the SV40-Renilla luciferase activity of a cotransfected internal standard. The ratio of the activity of Lwt to that of Lm1,2 was plotted as a function of the amount of cotransfected thioredoxin plasmid. The error bars indicate standard deviations. +, present; -, absent.

serum allowed the formation of specific complexes (Fig. 4A, lanes 4 and 8), these were completely inhibited by anti-GABP $\alpha$ (lanes 1 and 5) and partially inhibited by anti-GABP $\beta$ (lanes 2 and 6) for both probes, fp1 as well as fp2 (Fig. 4A). Conversely, to show that the fp1 and fp2 sequences can be bound by GABP, the corresponding oligonucleotides were incubated with recombinant $\mathrm{GABP} \alpha$ or $-\beta$, or with both together, and displayed in a gel retardation assay in parallel with the product of incubation with a nuclear extract of A20 cells (Fig. 4B and C). The addition of both $\alpha$ and $\beta$ subunits of GABP resulted in the formation of a complex with each of the probes (fp1 [Fig. $4 \mathrm{~B}$, lane 2] and fp2 [Fig. 4C, lane 3]) that comigrated with those formed upon addition of nuclear extracts (Fig. 4B, lane 4 , and $\mathrm{C}$, lane 1 ). As GABP $\beta$ is not a DNA-binding protein, the faster-migrating complex is considered nonspecific.
$\mathrm{GABP} \alpha$ bound less well than $\alpha$ and $\beta$ together, in agreement with the observation of a strong stabilizing effect of GABP $\beta$ on the DNA-binding activity of $\alpha(19,23)$. The major complex (I) formed by the nuclear extract comigrated with the $\alpha \beta$ complex of recombinant proteins, confirming the identification of $\mathrm{fp} 1$ and $\mathrm{fp} 2$ as GABP binding sites. We could not convincingly demonstrate an effect of a PEA3-specific antiserum on any retarded complex of nuclear extracts with either probe, consistent with the reports that PEA3 is normally expressed in epithelial cells (61) and myoblasts (57) but not in B lymphocytes (J. A. Hassell, personal communication).

Redox sensitivity of the complexes. DNA binding and heterodimer formation of GABP are sensitive to redox. Both functions require reducing conditions, and they are inhibited by pro-oxidant agents both intracellularly and in nuclear ex- 
A

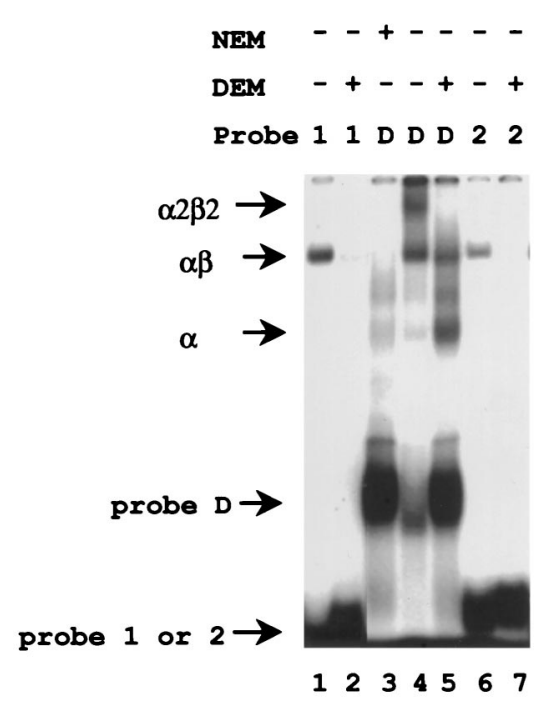

B

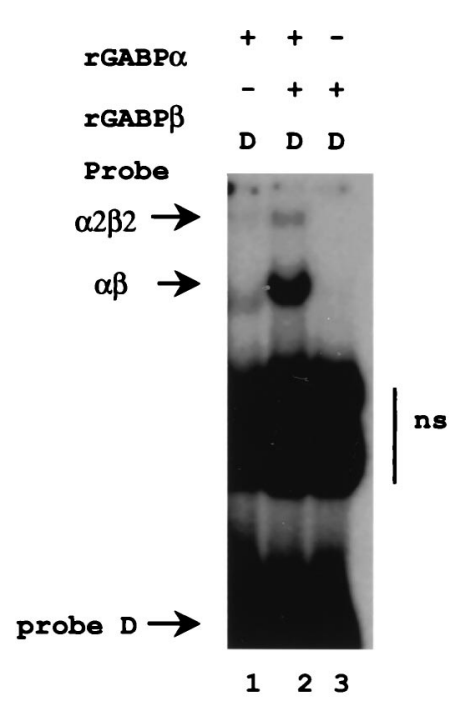

FIG. 5. Redox-sensitive GABP tetramers are formed by B-cell nuclear extracts on a probe containing both fp1 and fp2. (A) Gel retardation assay with A20 nuclear extracts and oligonucleotide probe fp1 (1), fp2 (2), or fp1-fp2 (D; see Fig. 2B). With probe D, a slower-migrating band is detected (lane 4). By analogy to the complex formed by recombinant GABP, and to those observed with similarly arranged Ets sites of known genes, it is tentatively identified as the tetrameric from of GABP and is labeled $\alpha 2 \beta 2$. Treatment with alkylating agents eliminated the tetrameric complex, in vitro by adding $\mathrm{NEM}\left(20 \mathrm{~min} ; 20^{\circ} \mathrm{C}\right)$ to the binding reaction (lane 3 ) or in vivo by using a nuclear extract of DEM-treated cells (lane 5). On the single-site probes as well, DEM treatment of the cells used for the nuclear extract eliminated the $\alpha \beta$ complex (lanes 2 versus 1 and 7 versus 6). (B) For comparison, tetramer formation on probe D by a mixture of recombinant GABP $\alpha$ (rGABP $\alpha$ ) and GABP $\beta$ (lane 2). +, present; -, absent. ns, nonspecific complex.

tracts $(15,45)$. We tested whether this applied to the complexes of B-cell extracts with $\mathrm{fp} 1$ and $\mathrm{fp} 2$. Nuclear extracts of A20 cells were treated in vitro with increasing amounts of the alkylating agent $N$-ethylmaleimide (NEM) or of DTT as a control and then used in mobility shift assays with the fp1 or fp2 probes. The results are shown in Fig. 4D and E. The lowest concentration $(0.25 \mathrm{mM})$ of NEM caused a reduction in the intensity of the $\alpha \beta$ dimer band compared to that under reducing conditions (Fig. 4D and E, lanes 3 versus 6). Moreover, it induced the appearance of a complex with higher mobility. We think it may contain the $\alpha$ subunit alone, consistent with the observation that the protein-protein interactions between the $\alpha$ and $\beta$ subunits are more sensitive to oxidative conditions than the binding of GABP $\alpha$ to DNA (15). Increasing NEM concentrations resulted in the disappearance of both DNA- $\alpha \beta$ and DNA- $\alpha$ complexes (Fig. 4D and E, lane 1). We also tested the sensitivity of the fp1-fp2 binding activity to intracellular redox changes. A20 cells were treated for $2 \mathrm{~h}$ with the glutathione-depleting agent DEM before nuclear extracts were prepared (45). These in vivo-treated extracts, similarly to the in vitro NEM-treated samples, were unable to form a complex with either fp1 or fp2 (Fig. 5A, lane 2 versus lane 1 and 7 versus $6)$. Finally, it has been shown that the reducing protein thioredoxin regulates the DNA-binding activity of GABP (45) and the transcriptional activity of the glucocorticoid receptor (44). We therefore measured the activity of the luciferase reporter with either the wild-type or the fp1-fp2-mutated LTR in M12 cells cotransfected with a plasmid expressing thioredoxin and pretreated with $\mathrm{H}_{2} \mathrm{O}_{2}$ (Fig. $4 \mathrm{~F}$ ). To assess the contribution of the fp1-fp2 mutation, the ratio of the activities (wild-type LTR over mutated LTR) was plotted in Fig. $4 \mathrm{~F}$ as a function of the amount of cotransfected thioredoxin plasmid. In its absence, no response to dexamethasone was observed (ratio, 1). The intracellular expression of thioredoxin reestablished the hormonal response of the wild-type LTR but not that of the mutated LTR (ratio, $>1$ ). These data show that the fp1-fp2 binding activity is regulated by redox conditions in vitro and in vivo, in agreement with its identification as GABP.

Formation of heterotetrameric complexes. GABP forms an $\alpha 2 \beta 2$ tetramer on tandemly arranged sites (like those in the immediate-early promoter of herpes simplex virus) through a leucine zipper domain at the carboxyl terminus of GABP $\beta$ (19). As fp1 and fp2 form an analogous arrangement in the MMTV LTR, separated by $8 \mathrm{bp}$, we investigated the binding properties of a double-stranded oligonucleotide comprising both $\mathrm{fp} 1$ and $\mathrm{fp} 2$. In a gel retardation assay, a complex with very low mobility is clearly visible (Fig. 5A, lane 4) above the $\alpha \beta$ band. It is tentatively identified as $\alpha 2 \beta 2$, although its stoichiometry is not known. A complex with the same mobility was detected with recombinant $\mathrm{GABP} \alpha$ plus $-\beta$ (Fig. 5B, lane 2), whereas the addition of $\mathrm{GABP} \alpha$ alone produced a faint lower band (possibly an $\alpha 2$ complex [Fig. 5B, lane 1]). In agreement with their putative identifications, both cellular $\alpha 2 \beta 2$ and $\alpha \beta$ complexes disappeared upon in vitro treatment of the nuclear extract with the alkylating agent NEM (Fig. 5A, lane 3). An extract from cells treated in vivo with DEM did not form any heterotetramers on the fp1-fp2 probe (Fig. 5A, lane 5), whereas some $\alpha \beta$ dimers, and predominantly $\alpha$ monomers, were detectable, suggesting that the in vivo oxidation of the relevant cysteines of GABP $\alpha$ had been incomplete. Compared to the total suppression of complex formation on single-site probes (Fig. 5A, lanes 2 and 7), the partial effect on the doublesite probe (Fig. 5A, lane 5) may be due to cooperativity of GABP binding. In conclusion, the DNA-binding activity to the fp1 and fp2 sites present in nuclear extracts of B-cell lines was identified as the heterodimeric Ets family member GABP, based on its electrophoretic mobility, reactivity with specific antisera, comigration with recombinant proteins, and sensitivity to redox conditions. 

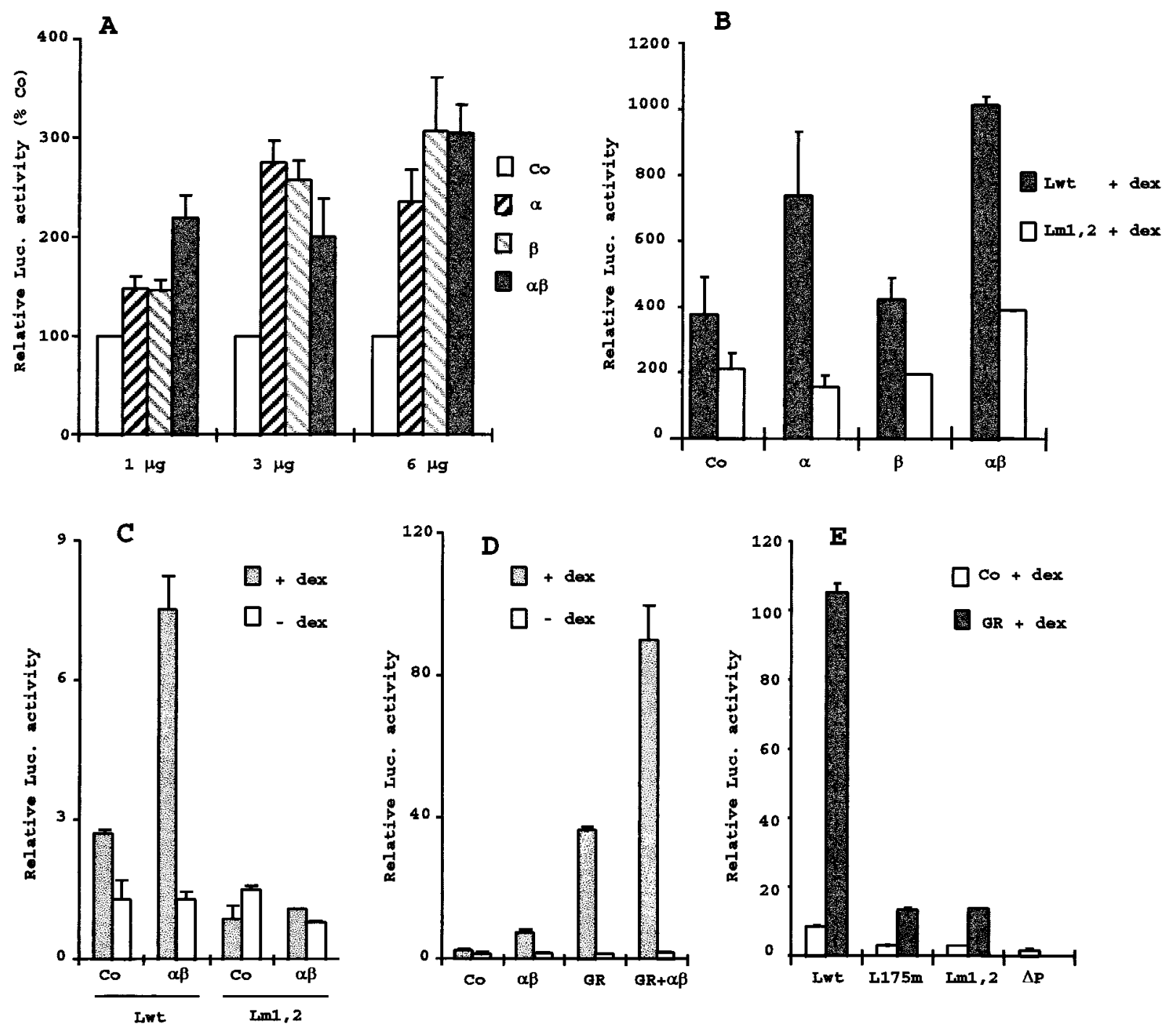

FIG. 6. Exogenous GABP increases glucocorticoid-stimulated reporter activity in M12 cells (A and C) and L cells (B) in an fp1-fp2-dependent manner (B and C); exogenous glucocorticoid receptor synergizes with GABP (D) and requires fp1 and fp2 (E) in M12 cells. (A) The expression plasmids sRSV-GABP $\alpha$ and/or sRSV-GABP $\beta 1(0,1,3$, or $6 \mu \mathrm{g})$ plus the control plasmid pRSV-TK $(\mathrm{Co})$ to a total amount of $12 \mu \mathrm{g}$ were transiently cotransfected with 0.75 pmol of wild-type LTR-(firefly) luciferase plasmid into M12 cells, which were treated with dexamethasone (50 nM). (B) $6 \mu \mathrm{g}$ of pRSV-TK (Co) or $3 \mu \mathrm{g}$ of sRSV-GABP $\alpha$ and/or sGABP $\beta 1$ plus pRSV-TK to a total of $6 \mu \mathrm{g}$ were cotransfected with 0.75 pmol of wild-type (Lwt) or fp1-fp2-mutated (Lm1,2) LTR-luciferase reporter constructs into Ltk ${ }^{-}$cells, which were treated with $100 \mathrm{nM}$ dexamethasone $(+\mathrm{dex})$. (C) Three micrograms each of sRSV-GABP $\alpha$ and sRSV-GABP $\beta 1$ expression plasmids $(\alpha \beta)$ or $6 \mu \mathrm{g}$ of pRSV-TK $(\mathrm{Co})$ was cotransfected with 0.75 pmol of wild-type $(\mathrm{Lwt})$ or fp1-fp2-mutated $(\mathrm{Lm} 1,2)$ LTR-luciferase constructs into M12 cells, which were treated $(+$ dex $)$ or not (- dex) with dexamethasone $(50 \mathrm{nM})$. (D) Synergistic effect of GABP and the glucocorticoid receptor (GR). M12 cells were transfected with 0.75 pmol of Lwt plus $9 \mu \mathrm{g}$ of pRSV-TK (Co) or $3 \mu \mathrm{g}$ each of sRSV-GABP $\alpha$ and sRSV-GABP $\beta 1(\alpha \beta)$ and/or $3 \mu \mathrm{g}$ of pRSVhGR $\alpha$ (GR). pRSV-TK was added to a total amount of $9 \mu \mathrm{g}$ per transfection. The cells were treated (+ dex) or not $(-\mathrm{dex})$ with $50 \mathrm{nM}$ dexamethasone. (E) Overexpressed glucocorticoid receptor required fp1 and fp2 as well as the GRE for glucocorticoid stimulation in M12 cells. Three micrograms of pSG5mGR (GR) or of pSV2-neo control plasmid (Co) was cotransfected with 0.75 pmol of LTR-luciferase constructs containing either the wild-type LTR (Lwt), an LTR with the mutation LS 175/-166 in the GRE (L175m), the fp1-fp2-mutated LTR $(\mathrm{Lm} 1,2)$, or the promoterless $\Delta \mathrm{P}$ plasmid as a negative control. The cells were treated with $50 \mathrm{nM}$ dexamethasone. In panel $\mathrm{E}$, the firefly luciferase (Luc.) activities of the extracts were measured and normalized to the SV40-Renilla luciferase activity of a cotransfected internal standard. In panels A to D, the luciferase activity is expressed in arbitrary units with respect to the protein content. Individual experiments are shown, which have been repeated with the same results at least twice. The error bars show the standard deviations between duplicate samples.

Functional cooperation of GABP with the glucocorticoid response. We have shown (Fig. 3) that mutations which prevent GABP binding to the fp1 and fp2 sites abolished the transcriptional stimulation elicited by dexamethasone in B-cell lines. As the fp1 and $\mathrm{fp} 2$ sites are contiguous to the distal GRE, which mediates the glucocorticoid response (Fig. 3D), the endogenous GABP of B cells may improve the binding or the activation properties of the glucocorticoid receptor. To test if added exogenous GABP is able to further increase the stimu- lated expression from the MMTV-LTR-luciferase reporter plasmid, we cotransfected M12 cells with expression vectors for the cDNAs of the GABP subunits, singly or together. As shown in Fig. 6A, a twofold increase in luciferase activity was observed even with the lowest dose $(1 \mu \mathrm{g})$ of GABP plasmids, especially with both subunits. Single subunits were also effective, probably in cooperation with endogenous GABP. With increasing amounts of GABP ( 3 or $6 \mu \mathrm{g}$ ), a maximum increase of approximately threefold was obtained, approaching a pla- 
teau. For comparison, we cotransfected the same plasmids into $\mathrm{Ltk}^{-}$cells, which contain a relatively large amount of glucocorticoid receptor (Fig. 1) (47) but do not show any presence of GABP in mobility shift assays with the fp 1 or $\mathrm{fp} 2$ probe or with a consensus GABP binding probe (not shown). The results (Fig. 6B) show an fp1- and fp2-dependent increase of dexamethasone-induced reporter activity of approximately twofold with either GABP $\alpha$ alone or $\alpha$ plus $\beta$; GABP $\beta$ alone had no effect, consistent with its inability to bind DNA and with the absence of endogenous GABP $\alpha$ in L cells. In M12 cells as well, the increase of dexamethasone-stimulated activity by $\mathrm{GABP} \alpha \beta$ was dependent on the fp1 and $\mathrm{fp} 2$ sequences, whereas no effect was observed on the uninduced basal level (Fig. 6C). We conclude that GABP is able to cooperate functionally with the endogenous glucocorticoid receptor. Since the expression of exogenous GABP in M12 B cells showed a saturation of reporter activity (Fig. 6A), the level of endogenous receptor may be limiting. We therefore asked if the dexamethasone response could be improved by expressing exogenous receptor and if its action remained dependent on GABP. The results shown in Fig. 6D indicate that cotransfection of an expression vector for the glucocorticoid receptor increased the dexamethasone response of M12 cells approximately 15-fold and moreover cooperated synergistically with coexpressed GABP. This remarkable increment was dependent on the GRE (as expected) but also, to a similar extent, on the fp1 and fp2 motifs (Fig. 6E).

\section{DISCUSSION}

In this study, we have identified a novel regulatory region in the MMTV promoter that contains tandem Ets-like binding motifs and interacts with the heterodimeric Ets factor GABP present in mature B-cell lines. In these cells, mutation of both GABP binding sites abolished the transcriptional stimulation elicited by glucocorticoid hormones, and expression of exogenous GABP increased it, indicating a functional cooperation with the glucocorticoid receptor bound to the adjacent GRE. The GABP binding site in MMTV DNA between positions -140 and -165 is composed of a dyad symmetry element with the $\operatorname{GGA}(\mathrm{A} / \mathrm{T})$ core sequences directed to the center of the dyad. Of the two components of the dyad, fp1 shows a better homology ( 8 out of $10 \mathrm{bp}$ ) to the optimal GABP binding site (10), whereas fp2 is less related (5 out of $10 \mathrm{bp}$ ). This may explain their different efficiencies at binding recombinant GABP (Fig. 4B and C). A similar internal arrangement of the dyad is found in the GABP site of the distal IL-2 enhancer, and it was described as rather unfavorable for the formation of $\alpha 2 \beta 2$ heterotetramers (3). Indeed, recombinant $\alpha 2 \beta 2$ complexes were only a minor fraction of those formed on the fp1-fp2 oligonucleotide (Fig. 5). Structural features of the DNA-protein contacts have been described for a direct repeat of core elements $(6,28)$. On the other hand, a palindrome with the core elements directed in opposite directions, as in the IL-16 promoter, was shown to favor heterotetramer formation (4). A relative autonomy of the individual $\alpha \beta$ dimers on each site is suggested by the functional analysis of reporters carrying mutations in either fp 1 or $\mathrm{fp} 2$ that showed additivity and not synergism of their activities (Fig. 3A and B). At first sight, the function of the GABP binding sequences might seem to be to stabilize the binding of glucocorticoid receptor molecules on the GRE, especially if they are present in low abundance, as suggested by the absence of a footprint over the GRE with M12 nuclear extracts (Fig. 1). However, overexpression of the receptor was unable to overcome the need for GABP binding, and the integrity of the GABP sites was still required as much as the integrity of the GRE (Fig. 6E). With mutants either in the GRE or in the fp1-fp2 sequence, the residual activity observed with overexpressed receptor might be due to proteinprotein interactions between the receptor and GABP. These data suggest that the role of GABP in B cells goes beyond a mere stabilization of receptor binding to DNA and may involve a transactivation function. Moreover, coexpression of GABP and receptor resulted in a synergistic enhancement of the hormone response (Fig. 6D). An autonomous transactivating domain is present in the $\beta$ subunit of GABP, but none has been described so far in the $\alpha$ subunit $(30,53)$. On the other hand, it was the $\alpha$ subunit which showed cooperativity with endogenous glucocorticoid receptor in the transfection experiment with L cells (Fig. 6B). It is likely that the fp1 and fp2 sites are also occupied by Ets factors in $\mathrm{Ltk}^{-}$cells, because their mutation decreased the dexamethasone-induced luciferase level by two- to threefold. These putative Ets factors should be different from $\mathrm{GABP} \alpha$, as they cannot cooperate with transfected GABP $\beta$ (Fig. 6B) and can be replaced by GABP $\alpha$ more efficiently, probably because of its overexpression. Identifying the domains in GABP that are responsible for cooperation with the glucocorticoid response will give new insights into the complexity of the mechanisms of MMTV gene regulation by protein-protein interactions. Candidate proteins for conferring transactivation functions on GABP in the context of the MMTV promoter are the nuclear coactivators CBP and p300 (reviewed in reference 35), which were recently shown to bind to $\mathrm{GABP} \alpha$ and enhance the induction of the IL-16 promoter (4). The prototype Ets factor, Ets-1, was also shown to cooperate with $\mathrm{CBP}$ and $\mathrm{p} 300$, though the synergism was modest, suggesting that further cell or promoter requirements and/or factors are needed (63). It must be noted that the IL-16 promoter, like most promoters activated by GABP, lacks a TATA box, unlike to the MMTV promoter. Whether the mechanisms of transactivation would be the same when a steroid receptor plus GABP interacts with a TATA-box-containing promoter will have to be determined. GABP was found to be widely expressed in tissues $(19,37)$, yet it has been shown to command the regulation of several genes which are expressed in celltype-specific patterns. Such selectivity depends in part on the nature of the DNA-GABP $\alpha$ interactions and on regulation imparted by its association with GABP $\beta$ (28). Several of these genes contain neither a TATA box nor a classical initiator element, and GABP functions in them as a promoter element. In our study, no effect of mutations in $\mathrm{fp} 1$ and $\mathrm{fp} 2$ on the basal, uninduced transcriptional activity of the MMTV promoter was detected. In gel retardation assays with the fp1 or fp2 probe and nuclear extracts of mouse $\mathrm{Ltk}^{-}$cells, GR mammary tumor cells, or rat FTO-2B hepatoma cells, we did not detect any complex with the migration property of a GABP heterodimer (data not shown). It is a general characteristic of Ets factors to function in cooperation with other transcription factors (reviewed in reference 60). Among the partners described for GABP, one finds Jun-Fos (AP-1) (5), Sp-1 (64), c-Myb, and $\mathrm{C} / \mathrm{EBP}$ (48). Few reports are concerned with possible interactions of Ets factors with nuclear receptors. In the rat tyrosine aminotransferase gene, an Ets binding site of the $-2.5-\mathrm{kb}$ enhancer showed a weak cooperation with a neighboring GRE (22). A cross inhibition between exogenously expressed PU.1 (an Ets factor) and glucocorticoid receptor was observed with promoter constructs carrying the respective DNA regulatory elements (25). In the promoter of matrix metalloproteinases, an Ets binding site which is required for positive regulation in cooperation with an AP-1 site was shown to be the target of repression by the androgen receptor but not by other steroid (e.g., glucocorticoid) receptors (55).

Previous studies of regulatory functions of the MMTV LTR 
pointed to sequences in the -140 -to- -160 area as having negative effects, mainly on the basal level of transcription $(32,39$, 40). A report on an activity affecting the glucocorticoid stimulation in a particular rat hepatoma cell line showed a negative effect as well (56). These observations are in contrast to the role of fp1-fp2 in B cells described here, which is a positive one that affects the glucocorticoid-stimulated expression, not the basal level. In the course of its life cycle, MMTV replicates in lymphocytes, with B cells as the first targets of viral infection. Apart from the expression of the superantigen RNA encoded in the 3' LTR, for which separate promoters located in the env gene have been identified $(2,49,50,65)$, all other viral genes are transcribed from the major proviral promoter in the LTR. In a search for B-cell-specific transcriptional elements, it was not expected to find one that also relied on the glucocorticoid receptor. Our results suggest a necessary cooperation of GABP with the glucocorticoid receptor that may have biological relevance for cells containing low levels of receptor, like the mature B-cell lines used in this study. The basal activity of the MMTV promoter is higher in B-cell lines and in primary B cells than in mammary cells (16). Thus, two scenarios for MMTV expression seem to occur in vivo, one in mammary cells, consisting of a very low basal level with a very high hormonal stimulation of promoter activity, and one in B lymphocytes, characterized by a moderate basal level and a moderate glucocorticoid induction with the help of GABP, a nonreceptor factor. The data reported here concern a striking functional cooperation of GABP with the glucocorticoid receptor at a natural viral promoter. They provide the possibility to investigate the requirements for binding site arrangement and for specific protein domains. Moreover, as Ets factors in general (60), and GABP in particular (23), have been shown to be targets of the Ras-MAP kinase signal transduction cascade, they offer a novel example of regulatory possibilities at the intersection of two signaling pathways with a wide range of biological effects.

\section{ACKNOWLEDGMENTS}

We thank Egbert Flory for his generous gift of GABP reagents (expression vectors, recombinant proteins, and antisera), Isabelle Kerblat for the thioredoxin plasmid, and, for the glucocorticoid receptor plasmids, Ron Evans (human glucocorticoid receptor) and Malcolm Parker (mouse glucocorticoid receptor). We also thank our colleagues Eithne Costello and Roland Sahli for technical advice and Markus Nabholz and Roland Sahli for critical reading of the manuscript

This work was supported by the Swiss National Science Fund.

\section{REFERENCES}

1. Acha-Orbea, H., and H. R. MacDonald. 1995. Superantigens of mouse mammary tumor virus. Annu. Rev. Immunol. 13:459-486.

2. Arroyo, J., E. Winchester, B. S. McLellan, and B. T. Huber. 1997. Shared promoter elements between a viral superantigen and the major histocompatibility complex class II-associated invariant chain. J. Virol. 71:1237-1245.

3. Avots, A., A. Hoffmeyer, E. Flory, A. Cimanis, U. R. Rapp, and E. Serfling. 1997. GABP factors bind to a distal interleukin 2 (IL-2) enhancer and contribute to c-Raf-mediated increase in IL-2 induction. Mol. Cell. Biol. 17:4381-4389.

4. Bannert, N., A. Avots, M. Baier, E. Serfling, and R. Kurth. 1999. GA-binding protein factors, in concert with the coactivator CREB binding protein $/ \mathrm{p} 300$, control the induction of the interleukin 16 promoter in T lymphocytes. Proc. Natl. Acad. Sci. USA 96:1541-1546.

5. Basuyaux, J. P., E. Ferreira, D. Stehelin, and G. Butticè. 1997. The Ets transcription factors interact with each other and with the c-Fos/c-Jun complex via distinct protein domains in a DNA-dependent and -independent manner. J. Biol. Chem. 272:26188-26195.

6. Batchelor, A. H., D. E. Piper, F. C. de la Brousse, S. L. McKnight, and C. Wolberger. 1998. The structure of GABP $\alpha / \beta$ : an ETS domain-ankyrin repeat heterodimer bound to DNA. Science 279:1037-1041.

7. Beato, M. 1989. Gene regulation by steroid hormones. Cell 56:335-344.

8. Bittner, J. J. 1936. Some possible effects of nursing on the mammary gland tumor incidence in mice. Science 84:162-169.
9. Blake, M. C., R. C. Jambou, A. G. Swick, J. W. Kahn, and J. C. Azizkhan. 1990. Transcriptional initiation is controlled by upstream GC-box interactions in a TATAA-less promoter. Mol. Cell. Biol. 10:6632-6641.

10. Brown, T. A., and S. L. McKnight. 1992. Specificities of protein-protein and protein-DNA interaction of GABP $\alpha$ and two newly defined ets-related proteins. Genes Dev. 6:2502-2512.

11. Buetti, E. 1994. Stably integrated mouse mammary tumor virus long terminal repeat DNA requires the octamer motifs for basal promoter activity. Mol. Cell. Biol. 14:1191-1203.

12. Buetti, E., and B. Kühnel. 1986. Distinct sequence elements involved in the glucocorticoid regulation of the mouse mammary tumor virus promoter identified by linker scanning mutagenesis. J. Mol. Biol. 190:379-389.

13. Cardiff, R. D., and L. J. T. Young. 1980. Mouse mammary tumor biology: a new synthesis, p. 1105-1114. In M. Essex, G. Todaro, and H. Zur Hausen (ed.), Viruses in naturally occurring cancers. Cold Spring Harbor Laboratory, Cold Spring Harbor, N.Y.

14. Cavin, C., and E. Buetti. 1995. Tissue-specific and ubiquitous factors binding next to the glucocorticoid receptor modulate transcription from the mouse mammary tumor virus promoter. J. Virol. 69:3759-3770.

15. Chinenov, Y., T. Schmidt, X. Y. Yang, and M. E. Martin. 1998. Identification of redox-sensitive cysteines in GA-binding protein- $\alpha$ that regulate DNA binding and heterodimerization. J. Biol. Chem. 273:6203-6209.

16. Corley, R. B., F. E. Lund, T. D. Randall, L. B. King, S. Doerre, and D. L. Woodland. 1992. Mouse mammary tumor proviral gene expression in cells of the B lineage. Semin. Immunol. 4:287-296.

17. Costello, E., P. Saudan, E. Winocour, L. Pizer, and P. Beard. 1997. High mobility group chromosomal protein 1 binds to the adeno-associated virus replication protein (Rep) and promotes Rep-mediated site-specific cleavage of DNA, ATPase activity and transcriptional repression. EMBO J. 16:59435954.

18. Danielsen, M., J. P. Northrop, and G. M. Ringold. 1986. The mouse glucocorticoid receptor: mapping of functional domains by cloning, sequencing and expression of wild-type and mutant receptor proteins. EMBO J. 5:25132522.

19. de la Brousse, F. C., E. H. Birkenmeier, D. S. King, L. B. Rowe, and S. L. McKnight. 1994. Molecular and genetic characterization of GABP $\beta$. Genes Dev. 8:1853-1865.

20. Dignam, J. D., R. M. Lebovitz, and R. G. Roeder. 1983. Accurate transcription initiation by RNA polymerase II in a soluble extract from isolated mammalian nuclei. Nucleic Acids Res. 11:1475-1489.

21. Dzuris, J. L., T. V. Golovkina, and S. R. Ross. 1997. Both T and B cells shed infectious mouse mammary tumor virus. J. Virol. 71:6044-6048.

22. Espinás, M. L., J. Roux, J. Ghysdael, R. Pictet, and T. Grange. 1994. Participation of Ets transcription factors in the glucocorticoid response of the rat tyrosine aminotransferase gene. Mol. Cell. Biol. 14:4116-4125.

23. Flory, E., A. Hoffmeyer, U. Smola, U. R. Rapp, and J. T. Bruder. 1996. Raf-1 kinase targets GA-binding protein in transcriptional regulation of the human immunodeficiency virus type 1 promoter. J. Virol. 70:2260-2268.

24. Galas, D. J., and A. Schmitz. 1978. DNAse footprinting: a simple method for the detection of protein-DNA binding specificity. Nucleic Acids Res. 5:31573170 .

25. Gauthier, J. M., B. Bourachot, V. Doucas, M. Yaniv, and F. Moreau-Gachelin. 1993. Functional interference between the Spi-1/PU.1 oncoprotein and steroid hormone or vitamin receptors. EMBO J. 12:5089-5096.

26. Giguère, V., S. M. Hollenberg, M. G. Rosenfeld, and R. M. Evans. 1986. Functional domains of the human glucocorticoid receptor. Cell 46:645-652.

27. Gorski, K., M. Carneiro, and U. Schibler. 1986. Tissue-specific in vitro transcription from the mouse albumin promoter. Cell 47:767-776.

28. Graves, B. J. 1998. Inner workings of a transcription factor partnership. Science 279:1000-1002.

29. Grosschedl, R., and D. Baltimore. 1985. Cell-type specificity of immunoglobulin gene expression is regulated by at least three DNA sequence elements. Cell 41:885-897.

30. Gugneja, S., J. V. Virbasius, and R. C. Scarpulla. 1995. Four structurally distinct, non-DNA-binding subunits of human nuclear respiratory factor 2 share a conserved transcriptional activation domain. Mol. Cell. Biol. 15:102111.

31. Günzburg, W. H., and B. Salmons. 1992. Factors controlling the expression of mouse mammary tumour virus. Biochem. J. 283:625-632.

32. Härtig, E., B. Nierlich, S. Mink, G. Nebl, and A. C. Cato. 1993. Regulation of expression of mouse mammary tumor virus through sequences located in the hormone response element: involvement of cell-cell contact and a negative regulatory factor. J. Virol. 67:813-821.

33. Held, W., G. A. Waanders, A. N. Shakhov, L. Scarpellino, H. Acha-Orbea, and H. R. MacDonald. 1993. Superantigen-induced immune stimulation amplifies mouse mammary tumor virus infection and allows virus transmission. Cell 74:529-540.

34. Higuchi, T. 1991. Recombinant PCR, p. 177-183. In M. A. Innis, D. H. Gelfand, J. J. Sninsky, and T. J. White (ed.), PCR protocols. Academic Press, San Diego, Calif

35. Janknecht, R., and T. Hunter. 1996. Versatile molecular glue. Transcriptional control. Curr. Biol. 6:951-954. 
36. Kühnel, B., E. Buetti, and H. Diggelmann. 1986. Functional analysis of the glucocorticoid regulatory elements present in the mouse mammary tumor virus long terminal repeat. A synthetic distal binding site can replace the proximal binding domain. J. Mol. Biol. 190:367-378.

37. LaMarco, K., C. C. Thompson, B. P. Byers, E. M. Walton, and S. L. McKnight. 1991. Identification of Ets- and notch-related subunits in GA binding protein. Science 253:789-792.

38. LaMarco, K. L., and S. L. McKnight. 1989. Purification of a set of cellular polypeptides that bind to the purine-rich cis-regulatory element of herpes simplex virus immediate early genes. Genes Dev. 3:1372-1383.

39. Langer, S. J., and M. C. Ostrowski. 1988. Negative regulation of transcription in vitro by a glucocorticoid response element is mediated by a transacting factor. Mol. Cell. Biol. 8:3872-3881.

40. Lee, J. W., P. G. Moffitt, K. L. Morley, and D. O. Peterson. 1991. Multipartite structure of a negative regulatory element associated with a steroid hormone-inducible promoter. J. Biol. Chem. 266:24101-24108.

41. Lichtsteiner, S., J. Wuarin, and U. Schibler. 1987. The interplay of DNAbinding proteins on the promoter of the mouse albumin gene. Cell 51:963973.

42. Liu, J., D. Bramblett, Q. Zhu, M. Lozano, R. Kobayashi, S. R. Ross, and J. P. Dudley. 1997. The matrix attachment region-binding protein SATB1 participates in negative regulation of tissue-specific gene expression. Mol. Cell. Biol. 17:5275-5287.

43. Luther, S. A., and H. Acha-Orbea. 1997. Mouse mammary tumor virus: immunological interplays between virus and host. Adv. Immunol. 65:139243.

44. Makino, Y., N. Yoshikawa, K. Okamoto, K. Hirota, J. Yodoi, I. Makino, and H. Tanaka. 1999. Direct association with thioredoxin allows redox regulation of glucocorticoid receptor function. J. Biol. Chem. 274:3182-3188.

45. Martin, M. E., Y. Chinenov, M. Yu, T. K. Schmidt, and X. Y. Yang. 1996. Redox regulation of GA-binding protein- $\alpha$ DNA binding activity. J. Biol. Chem. 271:25617-25623.

46. Maxam, A. M., and W. Gilbert. 1980. Sequencing end-labeled DNA with base-specific chemical cleavages. Methods Enzymol. 65:499-560.

47. Meulia, T., and H. Diggelmann. 1990. Tissue-specific factors and glucocorticoid receptors present in nuclear extracts bind next to each other in the promoter region of mouse mammary tumor virus. J. Mol. Biol. 216:859-872.

48. Nuchprayoon, I., C. P. Simkevich, M. Luo, A. D. Friedman, and A. G. Rosmarin. 1997. GABP cooperates with c-Myb and C/EBP to activate the neutrophil elastase promoter. Blood 89:4546-4554.

49. Reuss, F. U., and J. M. Coffin. 1995. Stimulation of mouse mammary tumor virus superantigen expression by an intragenic enhancer. Proc. Natl. Acad. Sci. USA 92:9293-9297.

50. Reuss, F. U., and J. M. Coffin. 1998. Mouse mammary tumor virus superantigen expression in B cells is regulated by a central enhancer within the pol gene. J. Virol. 72:6073-6082.

51. Ringold, G. M. 1985. Steroid hormone regulation of gene expression. Annu. Rev. Pharmacol. Toxicol. 25:529-566.
52. Rollini, P., J. Billotte, E. Kolb, and H. Diggelmann. 1992. Expression pattern of mouse mammary tumor virus in transgenic mice carrying exogenous proviruses of different origins. J. Virol. 66:4580-4586.

53. Sawada, J., M. Goto, C. Sawa, H. Watanabe, and H. Handa. 1994. Transcriptional activation through the tetrameric complex formation of E4TF1 subunits. EMBO J. 13:1396-1402.

54. Sawadogo, M., and R. G. Roeder. 1985. Interaction of a gene-specific transcription factor with the adenovirus major late promoter upstream of the TATA box region. Cell 43:165-175.

55. Schneikert, J., H. Peterziel, P. A. Defossez, H. Klocker, Y. Launoit, and A. C. Cato. 1996. Androgen receptor-Ets protein interaction is a novel mechanism for steroid hormone-mediated down-modulation of matrix metalloproteinase expression. J. Biol. Chem. 271:23907-23913.

56. Tanaka, H., Y. Dong, Q. Li, S. Okret, and J. A. Gustafsson. 1991. Identification and characterization of a cis-acting element that interferes with glucocorticoid-inducible activation of the mouse mammary tumor virus promoter. Proc. Natl. Acad. Sci. USA 88:5393-5397.

57. Taylor, J. M., E. E. Dupont-Versteegden, J. D. Davies, J. A. Hassell, J. D. Houle, C. M. Gurley, and C. A. Peterson. 1997. A role for the ETS domain transcription factor PEA3 in myogenic differentiation. Mol. Cell. Biol. 17: 5550-5558.

58. Toohey, M. G., J. W. Lee, M. Huang, and D. O. Peterson. 1990. Functional elements of the steroid hormone-responsive promoter of mouse mammary tumor virus. J. Virol. 64:4477-4488

59. van Leeuwen, F., and R. Nusse. 1995. Oncogene activation and oncogene cooperation in MMTV-induced mouse mammary cancer. Semin. Cancer Biol. 6:127-133

60. Wasylyk, B., J. Hagman, and A. Gutierrez-Hartmann. 1998. Ets transcription factors: nuclear effectors of the Ras-MAP-kinase signaling pathway. Trends Biochem. Sci. 23:213-216.

61. Xin, J. H., A. Cowie, P. Lachance, and J. A. Hassell. 1992. Molecular cloning and characterization of PEA3, a new member of the Ets oncogene family that is differentially expressed in mouse embryonic cells. Genes Dev. 6:481496.

62. Yanagawa, S., A. Murakami, and H. Tanaka. 1990. Extra mouse mammary tumor proviruses in DBA/2 mouse lymphomas acquire a selective advantage in lymphocytes by alteration in the $\mathrm{U} 3$ region of the long terminal repeat. J. Virol. 64:2474-2483.

63. Yang, C., L. H. Shapiro, M. Rivera, A. Kumar, and P. K. Brindle. 1998. A role for CREB binding protein and p300 transcriptional coactivators in Ets-1 transactivation functions. Mol. Cell. Biol. 18:2218-2229.

64. Yu, M., X. Y. Yang, T. Schmidt, Y. Chinenov, R. Wang, and M. E. Martin. 1997. GA-binding protein-dependent transcription initiator elements. Effect of helical spacing between polyomavirus enhancer a factor 3 (PEA3)/Etsbinding sites on initiator activity. J. Biol. Chem. 272:29060-29067.

65. Zhang, D. J., V. K. Tsiagbe, C. Huang, and G. J. Thorbecke. 1996. Control of endogenous mouse mammary tumor virus superantigen expression in SJL lymphomas by a promoter within the env region. J. Immunol. 157:3510-3517. 